\title{
UNA INMACULADA CONCEPCIÓN DE IGNACIO DE RÍES
}

\author{
A IMMACULATE CONCEPTION BY IGNACIO DE RÍES
}

\author{
José FeRnÁNDEZ LÓPEZ \\ Universidad de Sevilla. España \\ jflopez@us.es
}

\begin{abstract}
Este artículo presenta una nueva obra localizada de Ignacio de Ríes, pintor de la escuela sevillana de la primera mitad del siglo XVII. Se trata de la Inmaculada Concepción que figura en las dependencias actuales de la Hermandad y Cofradía del Santísimo Cristo de la Expiración de Morón de la Frontera (Sevilla). Estas dependencias fueron la antigua sede de la iglesia del colegio de la Compañía de Jesús en dicha población.

Palabras claves: Ignacio de Ríes; pintor; Inmaculada Concepción; Morón de la Frontera; Compañía de Jesús.
\end{abstract}

This paper presents an unknown work by the painter Ignacio de Ríes, artist of the Sevillian School of the first half of the $17^{\text {th }}$ century. It is the Immaculate Conception that is located in the current dependencies of the Brotherhood of the Holy Christ of the Expiration in Morón de la Frontera (Seville). These dependencies were the former headquarters of the church of the Society of Jesus School in that town. Jesus.

Kaywords: Ignacio de Ríes; painter; Immaculate Conception; Morón de la Frontera; Society of

Tras el decreto de expulsión de los jesuitas de los territorios de los reinos de España y la confiscación de sus bienes promulgado por orden de Carlos III, el 27 de febrero de 1767, el colegio de San Ignacio de Morón de la Frontera sufrió los avatares que con mayor o menor intensidad sufrieron todos los bienes inmuebles y muebles de la Compañía de Jesús en España y, en este caso que nos ocupa, en la archidiócesis sevillana. Finalmente el papa Clemente XIV, en el breve firmado el 21 de julio de 1773, Dominus ad Redemptor, suprimió el "Instituto y Orden de Clérigos Regulares, denominados Compañía de Jesús". En el conjunto de las providencias tomadas por el gobierno del reino relativas al extrañamiento y ocupación de los bienes jesuíticos en España, se promovió la realización de inventarios 
de pinturas para conocer la calidad de las mismas y evitar que las obras "de buenos Autores, que pueda haber en los Colegios de la Compañía, y se pongan a la venta [...] se saquen fuera del Reino". Esta recomendación fue hecha por el pintor de cámara de Carlos III Anton Raphael Mengs. En el caso del colegio de los jesuitas de Morón, el inventario de sus pinturas fue realizado con prontitud, pues la circular que instaba a realizar los mismos data del 16 de septiembre de 1767 y el inventario, redactado por Vicente Sánchez y Samariego, clérigo menor, entendido en artes y pinturas, ayudado por el administrador Ramón Núñez, fue rubricado en Morón por el escribano Juan Felipe de Ávila el 24 de septiembre de $1767^{1}$.

En el citado inventario se mencionan doce cuadros de la vida de la Virgen que servían y sirven de adorno a la iglesia del colegio, de siete cuartas de alto y nueve de largo, con marcos de madera de pino pintados de negro y filos dorados, sin que se precise o se reconozca estilo o autor de las mismas. En ese conjunto no figuraba ya dentro de la serie el lienzo de la Inmaculada Concepción cuya autoría proponemos, por lo que desde entonces, tanto por estilo como por ubicación física, no se consideraba del conjunto. Las antedichas doce pinturas, ya atribuidas a Pierter van Lint con anterioridad, fueron ratificadas en su autoría por Valdivieso ${ }^{2}$. Sin embargo, este autor señalaba en 1979: "En las doce pinturas que forman el conjunto que estudiamos se advierte un proceso de ejecución seriada en el que se diluye el estilo del artista por lo que su calidad es notablemente inferior a las obras realizadas de forma aislada y de manera más personal, sin tanta participación del taller. Por ello al lado de detalles excelentes que reflejan la personalidad del artista se advierten aspectos descuidados y torpezas propias de la intervención de manos auxiliares. Por otra parte se advierte también que estas pinturas son repeticiones de prototipos originales que Van Lint reproduciría con insistencia para atender la demanda del mercado pictórico destinado a la exportación"3.

En el citado inventario se señala también la presencia de "otro lienzo de la purísima Concepción de Nuestra Señora de cinco cuartas de alto y dos baras de

${ }^{1}$ HERNÁNDEZ GONZÁLEZ, Salvador: "Noticias en torno al establecimiento y supresión de la compañía de Jesús en Morón de la Frontera: Vicisitudes de su patrimonio artístico (ss. XVII-XX)", en Actas de las V Jornadas de Temas Moronenses. Sevilla, Fundación Fernando Villalón, 2003, pp. 161-175; y MARTÍN PRADAS, Antonio y CARRASCO GÓMEZ, Inmaculada: "El catálogo de pinturas del Colegio de San Ignacio de Morón de la Frontera (Sevilla)", Cuadernos de los Amigos de los Museos de Osuna, 16, 2014, pp. 114-119.

2 VALDIVIESO GONZÁLEZ, Enrique: "El pintor flamenco Pieter van Lint y su obra en la iglesia de la Compañía de Morón de la Frontera", en Actas de las V Jornadas de Temas Moronenses. Sevilla, 2003, pp. 216-217; y MARTIN PRADAS, Antonio y CARRASCO GÓMEZ, Inmaculada: "El catálogo de pinturas...", op. cit., p. 117.

3 VALDIVIESO GONZÁLEZ, Enrique: "Nuevas obras de Pieter Van Lint", Boletín del Seminario de Estudios de Arte y Arqueología, 45, 1979, pp. 469-479. 
ancho, con marco negro y su pintura ordinaria"4. Esta pintura se conserva actualmente en las dependencias de la Real y Antigua Hermandad de Gloria de la Santa Cruz y Cofradía de Nazarenos del Santísimo Cristo de la Expiración, Nuestra Señora de la Esperanza y San Ignacio de Loyola de Morón de la Frontera.

Con ocasión de la celebración de una exposición en el Círculo Mercantil e Industrial de Sevilla, en 2014, que mostraba el patrimonio de la citada corporación de penitencia moronense, se presentó el conjunto de lienzos atribuidos al pintor flamenco Pieter Van Lint, realizados a mediados del siglo XVII. La iglesia y su patrimonio fueron cedidos a la hermandad por el cardenal de Sevilla don Eustaquio Ilundain, haciéndose cargo esta del culto y mantenimiento de la iglesia. En este conjunto de los lienzos expuestos llamaba la atención un lienzo que representaba a la Inmaculada Concepción, citado anteriormente, cuya autoría artística era dispar al resto de cuadros que componían la serie, obras que, a nuestro entender, serían de taller y seguidoras del estilo de Peter van Lint (Amberes, 28 de junio de 1609-25 de septiembre de 1690), reconocido pintor barroco flamenco del siglo XVII, seguidor del estilo de Rubens. Sin embargo, el estilo del lienzo de temática inmaculadista responde al estilo y al quehacer del pintor de la escuela sevillana de la primera mitad del siglo XVII Ignacio de Ríes (Figura 1).

Ríes, ciertamente, fue un pintor de origen familiar flamenco, pero nació en Sevilla en 1616. Su padre, Mateo de Ríes, también pintor, se avecindó en Sevilla en 1628. Ignacio de Ríes fue, tal y como manifiesta su obra, discípulo de Zurbarán con quien se debió formar y colaborar en el obrador a partir de 1635-1636 y hasta, aproximadamente, 1645. Ríes desarrolló una intensa actividad artística, muy cercana a la comunidad de pintores flamencos en Sevilla. De 1661 datan las últimas noticias que se poseen de su vida y su trabajo ${ }^{5}$.

La labor pictórica de Ríes se centraba hasta hace algunos años en el conjunto de lienzos que adornaban la capilla del capitán Pedro Fernández de Miñano y Contreras situada en la catedral de Segovia. Los asuntos allí tratados -David tañendo el arpa, La conversión de San Pablo, El bautismo de Cristo, El Árbol de la Vida, La adoración de los pastores y La coronación de la Virgen, firmadas y fechadas todas en 1653- permiten conocer lo mejor del estilo de Ríes y su personalidad creativa. Efectivamente, su quehacer parte de Zurbarán pero, sin embargo, tiene una personalidad indiscutible, como demuestran estas pinturas, cuyo contenido

${ }^{4}$ MARTIN PRADAS, Antonio y CARRASCO GÓMEZ, Inmaculada: "El catálogo de pinturas...", op. cit., p. 118 .

${ }^{5}$ Sobre la vida y la obra de Ignacio de Ríes existe ya una consistente bibliografía tanto en aportaciones en artículos, obras colectivas e, incluso, una monografía de NAVARRETE PRIETO, Benito: Ignacio de Ríes. Madrid, 2001. Muy importantes son también las aportaciones de VALDIVIESO, Enrique: Historia de la pintura sevillana. Sevilla, 1986 (ed. 2002), p. 197; y VALDIVIESO, Enrique: Pintura Barroca Sevillana. Sevilla, 2003, pp. 298-302. 
iconográfico global alude al pecado, la conversión y otras escenas de la piedad católica.

El conjunto anteriormente citado supone lo mejor de la producción de Ignacio de Ríes. Sin embargo, en su obra podemos encontrar otras piezas de calidad como la Asunción de la Virgen de la parroquia de San Bartolomé de Sevilla, que lleva la fecha de 1661, obra inspirada en una estampa de Schelte Adams Bolswert basada en un original de Rubens. Similares características artísticas posee la Inmaculada que se conserva en la parroquia de San Ildefonso de Sevilla, lo que permite atribuirla claramente a Ríes. Un modelo similar a esta Inmaculada presenta la que se conserva en la zona alta del crucero de la iglesia del convento de las Teresas de Sevilla. Estas obras demuestran la personalidad de Ríes, que utiliza fórmulas grabadas que le permiten avanzar, a mediados del siglo XVII, hacia recetas creativas plenamente barrocas. Esto mismo va a ocurrir en obras como Camino al Calvario, perteneciente a una colección privada parisina, o en La Virgen del Rosario en los cielos, de la colección del Banco Bilbao Vizcaya, en Madrid, inspirada en una estampa atribuida a Mathias Grünewald ${ }^{6}$. Entre las obras más conocidas de Ríes, fechables hacia 1650-1655, figura el Arcángel San Miguel, del Metropolitan Museum de Nueva York, donde se atribuyó durante años a Zurbarán y a Antonio del Castillo. Actualmente, en las dependencias del Sagrario de la catedral de Sevilla, se encuentran dos lienzos de parejas de santos que representan a Santa Justa y Santa Rufina y a San Isidoro y San Leandro ${ }^{7}$. Finalmente, en este breve repaso por las obras más destacadas de este pintor, se ha identificado como de Ignacio de Ríes un Cristo crucificado, firmado "ygnaçio De Ries fae, $\mathrm{Se}^{\mathrm{a}}, \mathrm{a}^{\circ} 1646$ ", que se encuentra en el monasterio de Santa Teresa de Potosí (Bolivia).

El conocimiento de obras fundamentales en la trayectoria artística de Ignacio de Ríes ha permitido atribuirle otras pinturas que tienen su peculiar impronta, así como conocer con mayor precisión las características de su labor, calificada anteriormente solo como de la órbita zurbaranesca y que tiene, sin embargo, otros matices e influencias. Esto ocurre con la obra que presentamos, un óleo que muestra actualmente un pésimo estado de conservación, puesto que la superficie pictórica está reseca, craquelada, sucia y presenta bastantes lagunas pictóricas. Igualmente el lienzo está destensado, por lo que se impone una pronta intervención por parte de los equipos técnicos adecuados para su correcta conservación? 9 .

${ }^{6}$ SERRERA, Juan Miguel: “La Reina de los Cielos”, en Colección Central Hispano. Madrid, 1996, p. 58.

7 VALDIVIESO, Enrique: "Pintura de los siglos XVII al XX", en La Catedral de Sevilla. Sevilla, 1985, p. 429; y VALDIVIESO, Enrique: Historia de la pintura..., op. cit., p. 193.

8 RAMOS SOSA, Rafael: "Un Crucificado de Ignacio de Ríes en Potosí", Laboratorio de Arte, 27, 2015, pp. 605-610.

${ }^{9}$ Óleo sobre lienzo, 133 x $212 \mathrm{~cm}$. 
El lienzo muestra la presencia y la iconografía tradicional de la figura de la Inmaculada Concepción en el centro, vestida con túnica blanca, que se recoge en la cintura, cayendo a plomo sus pliegues hacia los pies. El manto es azul, de parecida disposición al modelo pictórico de Ríes en su Inmaculada de la parroquia de San Ildefonso de Sevilla, aunque con mayor movimiento. La figura descansa sobre la luna en cuarto menguante, desatendiendo el pintor en este caso los consejos del tratadista local Francisco Pacheco en su obra Arte de la Pintura ${ }^{10}$. El torso de la Virgen está dispuesto en ligera perspectiva y la cabeza inclinada hacia la derecha. Su rostro presenta rasgos característicos de los modelos femeninos de Ignacio de Ríes, con ojos bien abiertos y una leve sonrisa. Asimismo la cabellera es más escueta y no tan ensortijada como en el ejemplo de la parroquia sevillana antes citado. Las manos permanecen unidas ante el torso, sin entrelazarse (Figura 2).

Rodean a esta Inmaculada resplandores dorados orlados de nubes. En ellas se sitúan las presencias de ángeles niños, figuras de gran sentido dinámico y expresivo y valiente disposición compositiva, así como diversos símbolos marianos de las letanías lauretanas. Partiendo desde la zona inferior derecha encontramos el espejo, que porta el ángel inferior; el templo; las rosas, del ángel de la parte superior derecha; la escala; las azucenas del angelito superior izquierdo; la puerta situada tras él; la fuente; $y$, finalmente, delante del último símbolo, otro ángel niño con la torre (Figuras 3-4).

Observando la composición, el lienzo parece estar recortado, especialmente en la parte superior. Por sus características artísticas y la similitud de los modelos angélicos con los utilizados por Ríes en las pinturas de la capilla del capitán Contreras en la catedral de Segovia, la obra podría fecharse hacia 1650-1655.

Fecha de recepción: 30 de octubre de 2017

Fecha de aceptación: 30 de enero de 2018

${ }^{10}$ DE ALCÁZAR, P. Luis: Vestigatio Arcanu sensus in Apocalypsis. Amberes, 1604, cap. 12, vers. 1; BROWN, Jonathan: Painting in Seville from Pacheco to Murillo: A study of artistic transition. Michigan, 1964, p. 53; PACHECO, Francisco: Arte de la pintura. Madrid, 1956, pp. 211-212; y FERNÁNDEZ LÓPEZ, José: Programas iconográficos de la pintura barroca sevillana del siglo XVII. $2^{\mathrm{a}}$ ed. Sevilla, 2002, pp. 61-62. 


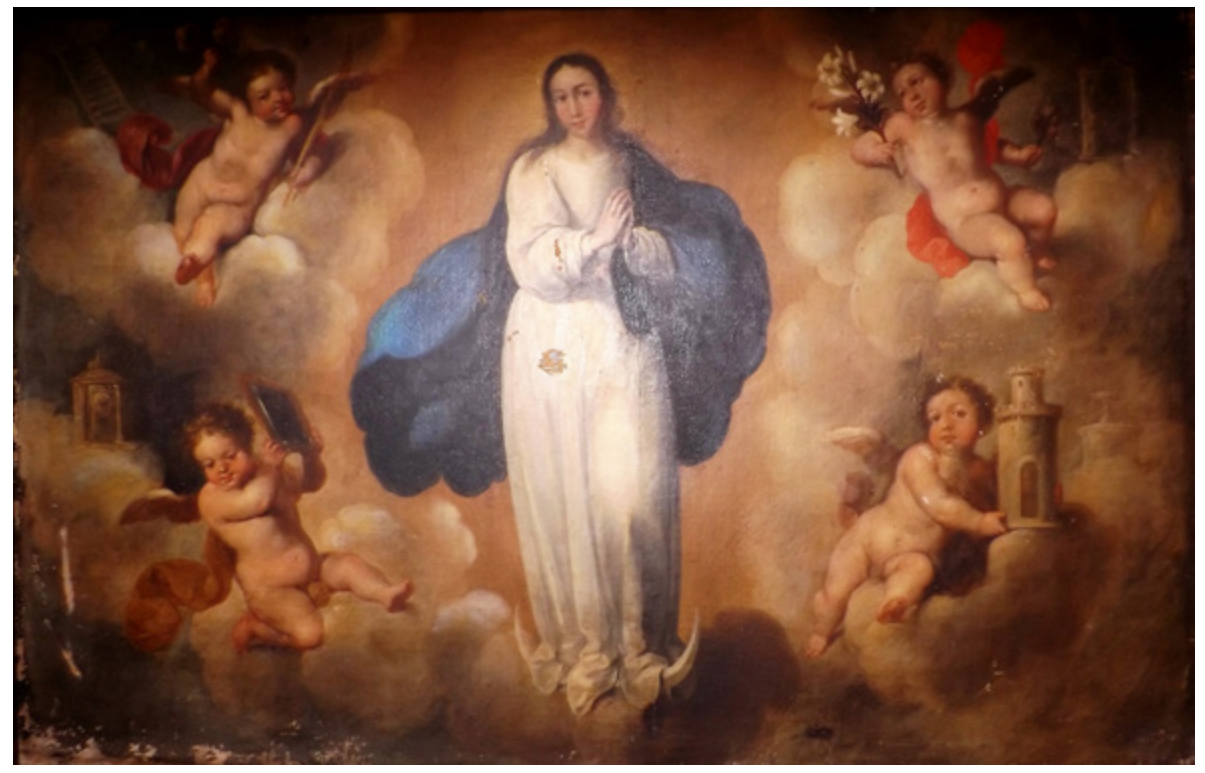

Figura 1. Ignacio de Ríes, Inmaculada Concepción, Hermandad del Santísimo Cristo de la Expiración, Morón de la Frontera. 


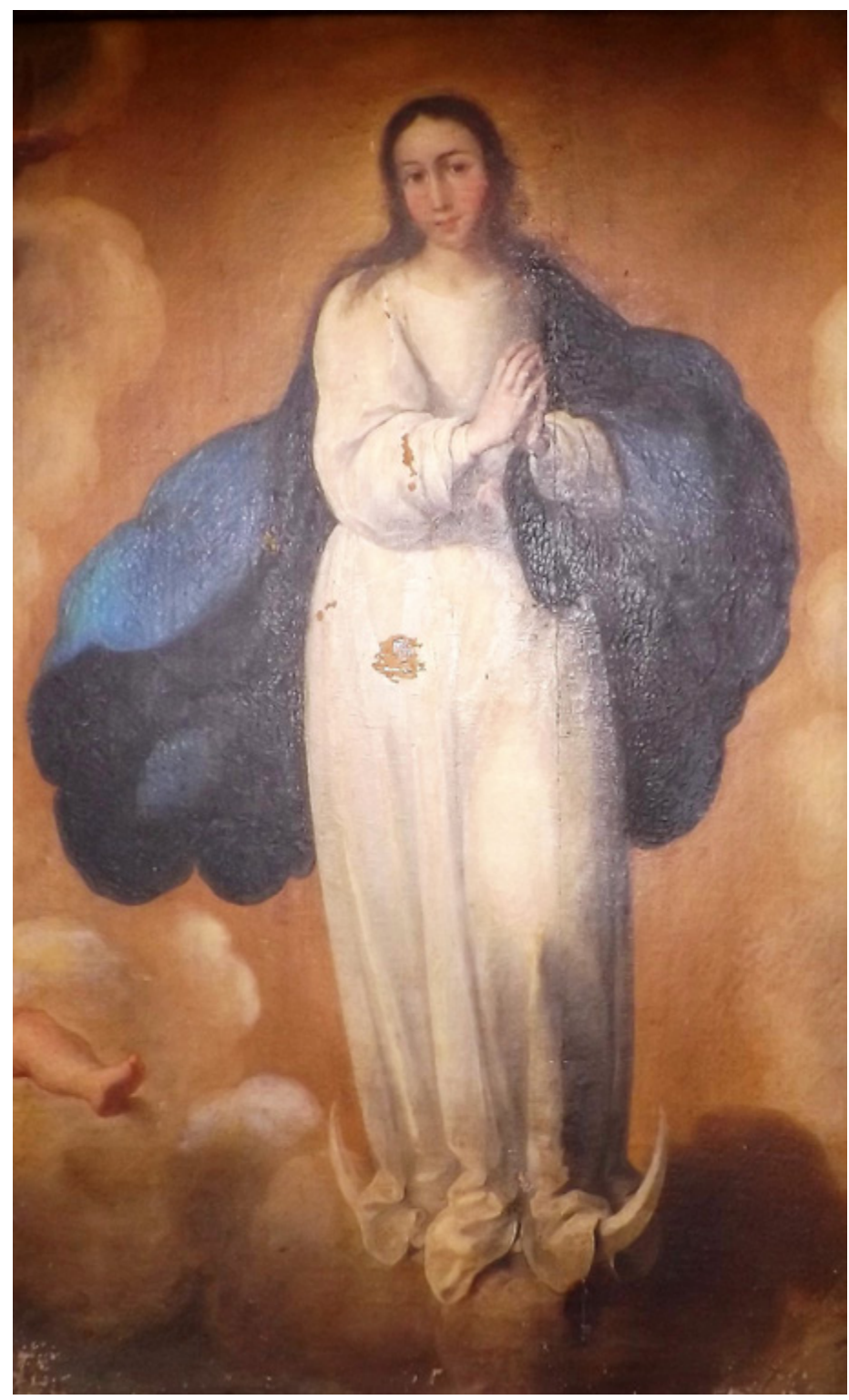

Figura 2. Ignacio de Ríes, Inmaculada Concepción (detalle central), Hermandad del Santísimo Cristo de la Expiración, Morón de la Frontera. 


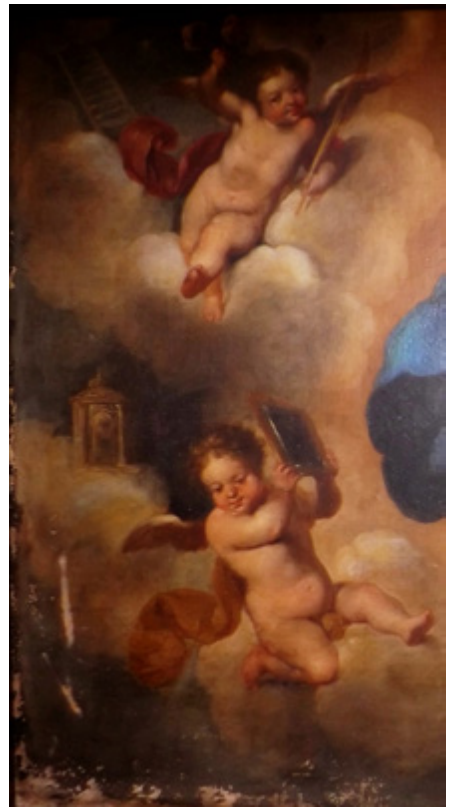

Figura 3. Ignacio de Ríes, Inmaculada Concepción (detalle lateral derecho de ángeles y símbolos marianos), Hermandad del Santísimo Cristo de la Expiración, Morón de la Frontera.

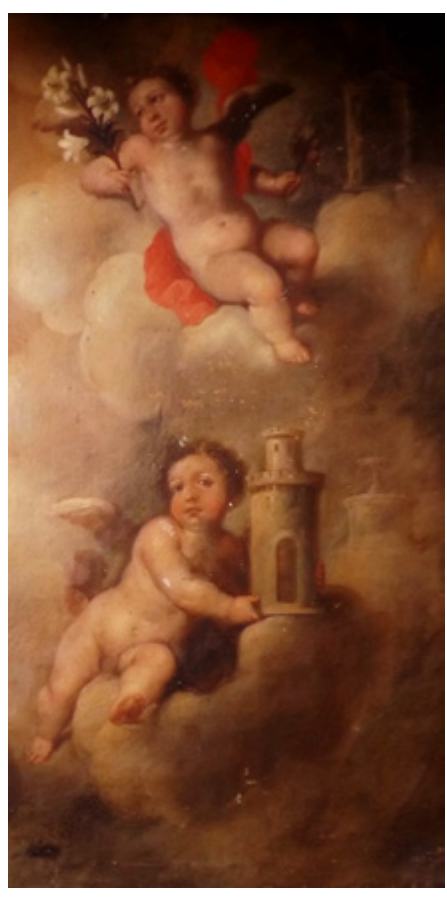

Figura 4. Ignacio de Ríes, Inmaculada Concepción (detalle lateral izquierdo de ángeles y símbolos marianos), Hermandad del Santísimo Cristo de la Expiración, Morón de la Frontera. 